\title{
MENGGUGAH KREATIVITAS SENI IBU-IBU PKK MELALUI SENI LUKIS PADA JILBAB DALAM RANGKA PELESTARIAN SENI
}

\author{
Iis Purnengsih, M. Sjafei Andrijanto, Ida Rosida \\ Fakultas Bahasa dan Seni \\ Universitas Indraprasta PGRI \\ iispurningsih@gmail.com,adreesj410@gmail.com RosiemKarim@gmail.com
}

\begin{abstract}
Abstrak
Kreativitas menyangkut penemuan sesuatu yang "seni" nya belum pernah terwujud sebelumnya (Djelantik, 1999: 71). Ide-ide kreatif memang tidak muncul begitu saja dari dalam otak kita, melainkan hasil dari interaksi kita dengan lingkungan. Apalagi di kalangan ibu-ibu rumah tangga. Menggugah kreativitas seni ibu-ibu rumah tangga memang tidak mudah, akan tetapi kreativitas mereka dapat dipancing melalui suatu kegiatan. Salah satu kegiatan yang dapat menggugah kreativitas seni ibu-ibu melalui suatu kegiatan melukis. Melukis adalah kegiatan yang tidak mudah dikerjakan, terutama untuk ibu-ibu. Namun melukis adalah kegiatan yang menyenangkan. Ini akan menjadi daya tarik ibu-ibu sehingga dengan melukis dapat menggugah kreativitas seni ibu-ibu. Media yang digunakan adalah kain jilbab bekas yang sudah jarang mereka pakai. Motif atau gambar yang diaplikasikan adalah motif-motif bunga yang umumnya motif yang disukai ibuibu. Target sasaran dalam rangka menggugah kreativitas seni ibu-ibu adalah ibu-ibu Pkk. Tujuan dari kegiatan pelatihan ini adalah untuk menggugah kreativitas seni ibu-ibu, selain itu kegiatan ini adalah salah satu wujud kami tim abdimas dalam upaya pelestarian seni.
\end{abstract}

Kata Kunci : Kreativitas, Pkk

\begin{abstract}
Creativity concerns the discovery of something that "art" has never been realized before (Djelantik, 1999: 71). Now creativity is very necessary, even in the world of work and business, we are required to creatively follow the development and progress of the era. Creative ideas do not just come out of our brain, but the result of our interaction with the environment. Especially among housewives. Raising the artistic creativity of housewives is not easy, but their creativity can be fished through an activity. As a form of our concern the team of Visual Communication Design of Indraprasta PGRI University to the community and because we are part of social interaction in society, therefore we offer creative ideas, one of which is the form of painting training on hijab cloth. The purpose of this training activity is to inspire the creativity of the art of mothers, besides this activity is one of our form of abdimas team in the effort of art
\end{abstract}

conservation. Keywords: Creativity, Pkk

\section{PENDAHULUAN}

Kreativitas menyangkut penemuan sesuatu yang "seni" nya belum pernah terwujud sebelumnya (Djelantik, 1999:
71). Apa yang dimaksudkan dengan seni' nya tidak mudah ditangkap, karena ini menyangkut sesuatu yang prinsipil dan konseptual. Yang dimaksudkan bukanlah hanya "wujud" yang baru, 
tetapi adanya pemahaman dalam konsep-konsep estetikanya sendiri, atau penemuan konsep yang baru sama sekali. Kini kreativitas memang sangat diperlukan, bahkan di dunia pekerjaan maupun bisnis, kita dituntut untuk kreatif mengikuti perkembangan dan kemajuan jaman. Kreativitas juga bukan dibawa saat kita lahir, bukan bawaan gen, melainkan tumbuh dari pikiran yang senantiasa dilatih.

Ide-ide kreatif memang tidak muncul begitu saja dari dalam otak kita, melainkan hasil dari interaksi kita dengan lingkungan. Apalagi di kalangan ibu-ibu rumah tangga, yang kesibukan sehari-hari nya mengurus rumah dan keluarga. Menggugah kreativitas seni ibu-ibu rumah tangga memang tidak mudah, akan tetapi kreativitas mereka dapat dipancing melalui suatu kegiatan. Pengabdian masyarakat atau abdimas termasuk dalam salah satu Tridarma dosen yang harus dilakukan setiap semester. Pada semester ini kami melakukan kegiatan abdimas dengan luaran yang dihasilkan yaitu lukisan pada kain jilbab. Kegiatan ini dilakukan di dua tempat dan dua mitra yang berbeda. Kedua mitra merupakan kelompok ibu-ibu Pkk. Kedua kelompok tersebut adalah Pkk Lestari dan Pkk Kenanga. Kegiatan ini dilakukan di Desa Cimandala Sukaraja Kab. Bogor, jarak ke lokasi 43,7 km dan Perum Adiwira Persada Bogor, jarak ke Lokasi 40,5 km. Kelompok Pkk Lestari dan Kelompok Pkk Kenanga terdiri dari kumpulan ibuibu yang umumnya adalah ibu rumah tangga yang kesehariannya disibukkan dengan mengurus rumah tangga nya. Karena kesibukan mereka mengurus rumah tangga, kadangkala mereka tidak punya ide untuk membuat kreasi seni dalam kegitan Pkk nya.

Berdasarkan hal tersebut, tim kami berinisiatif untuk membuat pelatihan mengenai seni lukis pada jilbab. Adapun tujuan dari abdimas ini adalah untuk menggugah kreativitas seni ibu-ibu Pkk Lestari dan ibu-ibu Pkk Kenanga. Material yang digunakan adalah jilbab ibu-ibu yang sudah tidak terpakai. Dengan tahapan-tahapan tertentu jilbab dilukis hingga jadi lebih menarik. Kegiatan ini juga dilakukan dalam rangka pelestarian seni.

Tujuan dari kegiatan abdimas adalah memberikan pelatihan kepada ibu-ibu Pkk Lestari dan ibu-ibu Pkk Kenanga untuk membuat hasil karya seni lukis menggunakan cat acrylic pada kain jilbab bekas. Hasil karya yang dihasilkan berupa jilbab bermotif bunga. Dengan pelatihan ini diharapkan dapat menggugah kreativitas seni ibu-ibu, sehingga jilbab mereka yang tidak terpakai bisa dipakai lagi dengan penampilan lebih menarik.

Manfaat kegiatan pengabdian masyarakat yang dilaksanakan di Pkk Lestari dan Pkk Kenanga adalah :

1. Menggugah kreativitas seni ibu-ibu Pkk.

2. Menambah pengetahuan ibu-ibu rumah tangga umumnya dan ibu-ibu Pkk khususnya.

3. Ikut serta dalam pelestarian seni terutama seni lukis.

4. Pemanfaatan limbah kain

5. Melalui kegiatan abdimas ini dapat mereka aplikasikan selanjutnya di rumah mereka.

Target dalam arti sasaran pengabdian masyarakat adalah kurang lebih dua puluh orang ibu-ibu anggota Pkk Lestari dan dua puluh orang ibu-ibu anggota Pkk Kenanga. Target dalam arti pencapaian yang dicanangkan dalam pengabdian masyarakat ini, bahwa setelah mengikuti kegiatan ini, diharapkan setiap anggota ibu-ibu Pkk :

1. Dengan cara pelatihan langsung, dapat menggugah kreatifitas seni ibu-ibu

2. Ibu-ibu Pkk jadi lebih kreatif. 
Adapun luaran (output) Pengabdian Masyarakat ini adalah dalam bentuk karya lukisan pada kain jilbab berupa motif bunga. Dengan menggunakan kain jilbab bekas dan dibuat oleh ibu-ibu Pkk Lestari dan ibu-ibu Pkk Kenanga yang ikut pelatihan, yang akan kami dokumentasikan sebagai arsip lalu kami masukkan dalam laporan. Untuk publikasinya kami masukkan laporan kegiatan Pengabdian Masyarakat ini dalam bentuk Jurnal.

Pelaksanaan kegiatan pengabdian masyarakat di Desa Cimandala Sukaraja Bogor dan Perum Adiwira Bogor berjalan dengan lancar. Pesertanya adalah ibu-ibu Pkk Lestari dan Pkk Kenanga. Kesuksesan kegiatan pelatihan ini karena sumber daya manusia yang handal dan menguasai bidangnya. Kualifikasi dari tim pengabdian masyarakat untuk kegiatan pelatihan ini antara lain Iis Purnengsih sebagai ketua tim,. M. Sjafei Andrijanto dan Ida Rosida sebagai anggota tim. Relevansi keilmuan bersifat linier yaitu mempunyai latar belakang pendidikan Desain Komunikasi Visual. Dengan kata lain, sinergisme kerja tidak sama-sama mengandalkan satu kemampuan kerja, melainkan pembagian kerja yang berdasarkan kemampuan khusus yang dimiliki oleh masing-masing anggota tim.

Dengan adanya posisi dan fungsi kinerja dari setiap tim ini, menjadi layak untuk bisa menghadapi, merumuskan hingga menyelesaikan suatu persoalan yang dihadapi ibu-ibu Pkk Lestari dan ibu-ibu Pkk kenanga, untuk memberikan pelatihan dan pengetahuan baru bagi guru-guru yang berhubungan dengan kreatifitas. Metode pelaksanaan yang digunakan melalui observasi terlebih dahulu, dan wawancara langsung dengan Ketua Pkk Lestari yaitu ibu Heru Winarningsih dan ketua Pkk Kenanga yaitu ibu Indasah apa yang dibutuhkan oleh ibu-ibu Pkk dan kami tim pengabdian akan berusaha untuk membantu menemukan solusi dan merealisasinya.

Sesuai pembicaraan tim dengan ibu Heru Winarningsih dan ibu Indasah, mereka menginginkan sesuatu yang belum pernah diajarkan, oleh sebab itu kami memberikan pelatihan teknik lukis pada jilbab menggunakan cat acrylic.

Proses pelaksanaan kegiatan Pengabdian kepada Masyarakat dilaksanakan selama 5 (lima) bulan, yaitu dimulai bulan Maret 2018 sampai dengan bulan Agustus 2018. Pelaksanaan diawali dengan observasi dan wawancara di gedung Pkk Lestari Dan gedung Pkk kenanga, kemudian dilanjutkan dengan menyusun materi penyuluhan dan pelatihan yang dilaksanakan pada hari Sabtu tanggal 12 Mei 2018 di kediaman salah satu anggota Pkk Lestari yaitu ibu Ristiyanti Marwoto jam 10.00 WIB sampai selesai.

Dalam Kegiatan ini, metode pelaksanaan dibagi lima tahap :

1. Tim melakukan observasi dan wawancara untuk mengetahui apa yang dibutuhkan oleh ibu-ibu Pkk.

2. Hasil dari tahap observasi, kemudian dijadikan bahan pertimbangan untuk memberikan pelatihan yang belum pernah ibu-ibu Pkk dapat, yaitu pelatihan teknik lukis dengan menggunakan cat acrylic.

3. Tahap selanjutnya kami mempersiapkan peralatan dan perlengkapan yang dibutuhkan untuk pelatihan teknik lukis dengan menggunakan cat acrylic.

4. Di dalam tahap pelatihan, diawal kami memberikan penjelasan mengenai teknik lukis dengan menggunakan acrylic, peralatan yang digunakan, tahapan demi tahapan dalam praktik teknik ini dari awal sampai akhir atau finishing. 
5. Pada pelatihan tersebut, para peserta atau ibu-ibu Pkk mencoba mempraktikkan teknik lukis dengan cat acrylic ini dengan mengikuti tahapan yang sudah dijelaskan. Hasil dari pelatihan ini dapat mereka bawa dan mereka bisa mempraktekannya ilmu yang didapat di rumah masingmasing.

6. Penulisan Laporan Pengabdian kepada masyarakat.

\section{PEMBAHASAN}

Pengabdian masyarakat ini diharapkan dapat membantu pihak mitra yaitu ibu-ibu Pkk Lestari dan ibu-ibu Pkk Kenanga untuk memberikan pengetahuan yang baru dalam teknik lukis dengan menggunakan cat acrylic pada jilbab bekas dan juga melalui pelatihan ini peserta dapat mengaplikasikannya dirumah. Pada hari pelaksanaan kegiatan pada tanggal 12 Mei 2018, dihadiri oleh ibu-ibu Pkk Lestari 8 orang dan ibu-ibu Pkk Kenanga 7 orang. Pelatihan ini diawali dengan kami sebagai tim abdimas memberikan penyuluhan, penjelasan kepada peserta mengenai teknik transfer laser print, ibu-ibu terlihat antusias dalam memperhatikan penjelasan kami. Untuk pelatihan ini kami memberikan alternatif dalam penggunaan cat acrylic yang mudah didapat dan terjangkau, agar peserta dapat terus mempraktikkan ilmu yang diberikan dari pelatihan ini. Pertama kami menjelaskan peralatan dan perlengkapan yang dibutuhkan dalam pelatihan, di antaranya :
1. Jilbab bekas

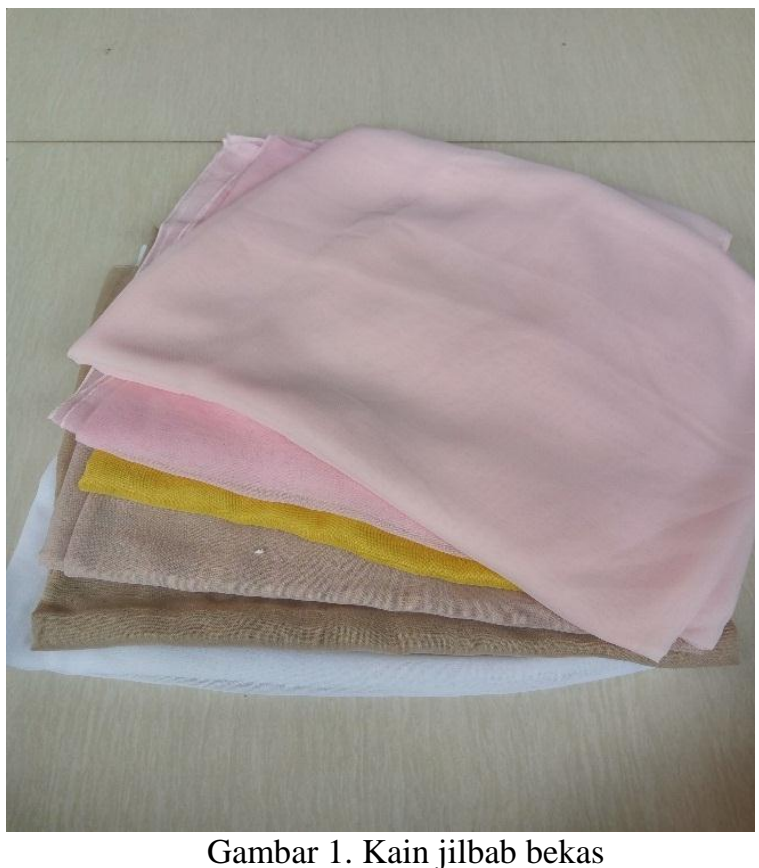

2. Cat Acrylic dengan berbagai warna dan berbagai macam ukuran kuas

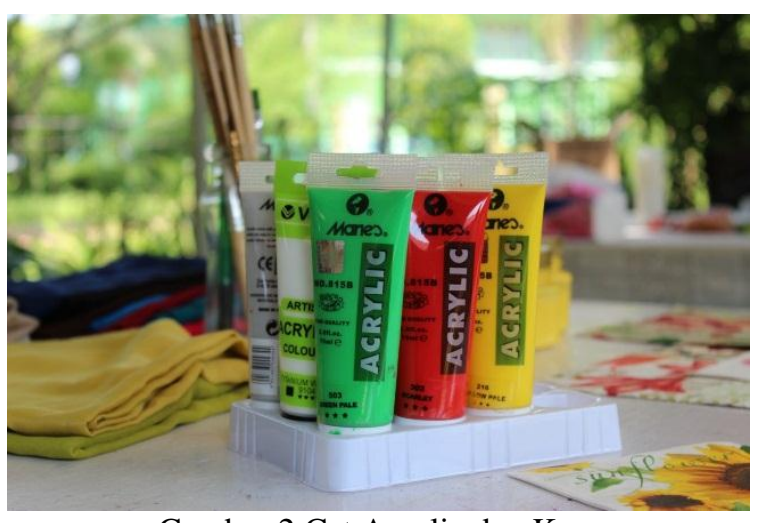

Gambar 2 Cat Acrylic dan Kuas

3. Tisyu bermotif ( untuk acuan gambar lukis)

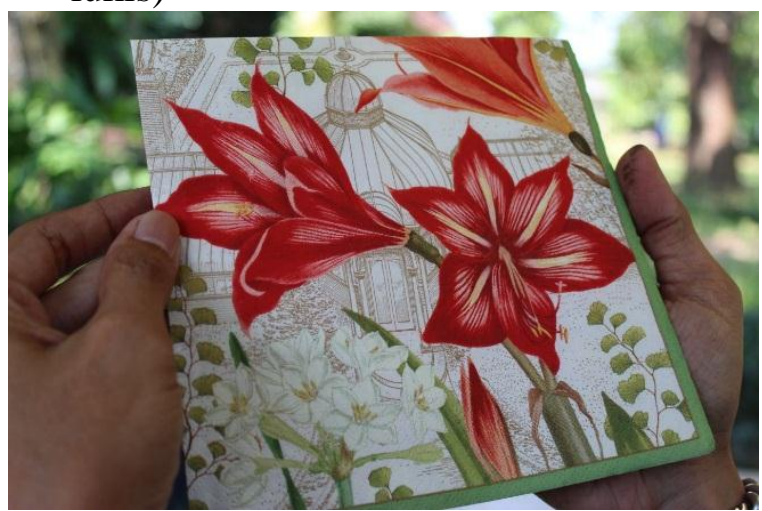

Gambar 3. Tisyu Motif 
4. Proses membuat sketsa

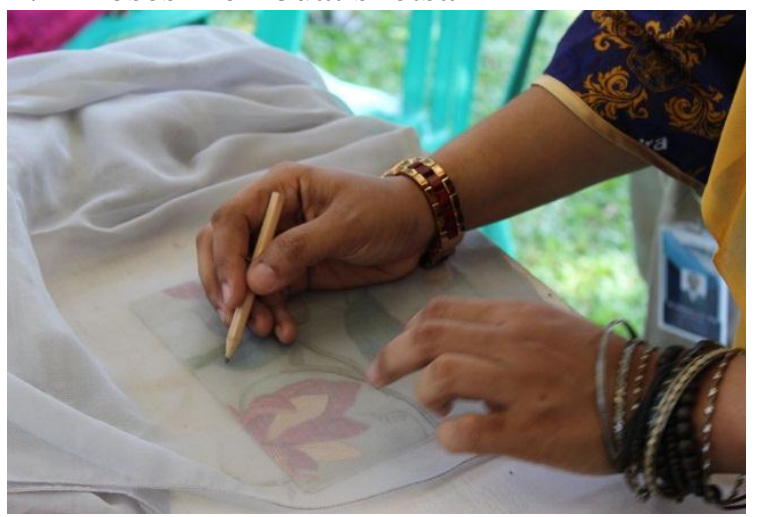

Gambar 4. Membuat Sketsa dengan cara dijiplak

\section{Proses melukis/ Pengecatan}

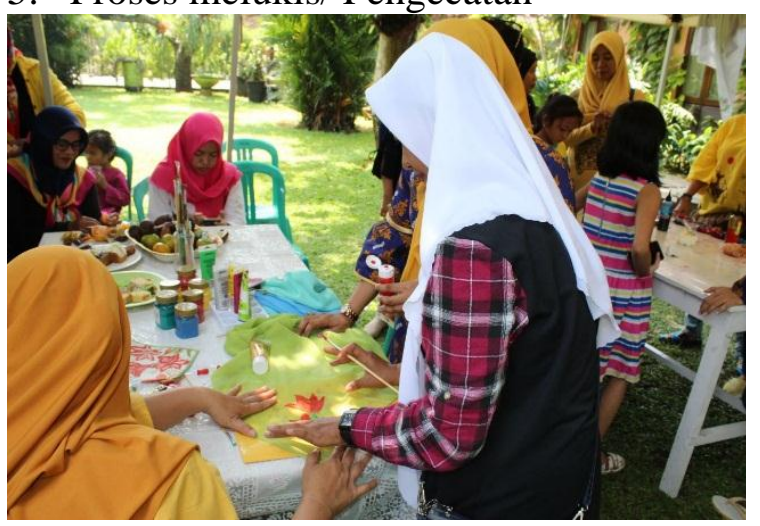

Gambar 5. Proses melukis pada kain jilbab

6. Hasil yang dicapai

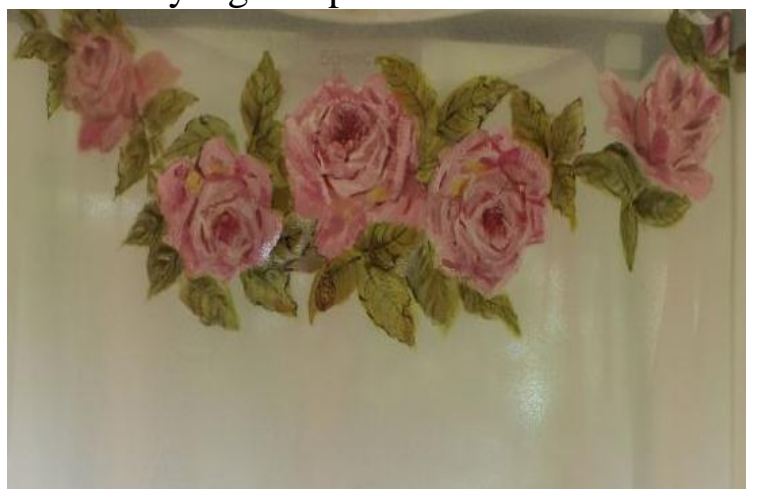

Gambar 6. Salah satu contoh kain jilbab yang sudah di lukis

Tim juga mempersiapkan segala kebutuhan peralatan dan perlengkapan pelatihan dari image yang digunakan sampai varnish untuk finishing. Di pelatihan ini image yang kami gunakan disesuaikan dengan selera ibu-ibu Pkk yaitu image motif bunga dengan menggunakan tisyu motif untuk diperagakan dan dicontohkan kepada para peserta pelatihan kegiatan abdimas ini, lalu mereka dipersilahkan untuk mempraktikan apa yang sudah kami jelaskan dan contohkan, dengan menggunakan peralatan dan perlengkapan yang telah kami sediakan untuk di coba langsung sendiri, ibu-ibu Pkk berusia beragam berkisar 35 sampai 45 tahun dan memiliki latar belakang ibu rumah tangga dan pemahaman yang berbeda-beda sehingga ada permasalahan yang dihadapi saat memberikan materi pelatihan menggunakan tisyu, yaitu : 1 . Ibu-ibu baru benar-benar baru mengetahui mengenai teknik ini, sehingga tim dosen harus menjelaskan secara detail mengenai teknik, tisyu yang digunakan pada saat membuat sketsa, media apa saja yang dapat digunakan dan langkahlangkah dalam pembuatan bahan ajar ini 2. Selama ini ibu-ibu beranggapan bahan motif pada kain harus di sablon, tapi dengan pelatihan ini ibu-ibu bisa membuat bahan ajar sendiri dengan gambar atau image yang mereka inginkan dan sukai.

Pelaksanaan kegiatan Pengabdian kepada Masyarakat dalam bentuk penyuluhan dan pelatihan teknik lukis pada jilbab dengan menggunakan cat acrylic sebagai salah satu cara untuk menggugah kreativitas seni ibu-ibu Pkk Lestari dan ibu-ibu Pkk Kenganga telah selesai kami laksanakan sesuai target. Sambutan dari ibu-ibu Pkk sangat baik dan antusias untuk pelatihan ini, karena pelatihan ini sesuatu yang belum mereka ketahui sebelumnya. Sebelum kegiatan abdimas ini dilaksanakan, ibu-ibu sama sekali belum mengenal teknik lukis pada jilbab seperti apa, namun setelah kami berikan penyuluhan, penjelasan dan pelatihan langsung, alhamdulillah mereka mengerti dan dapat melakukan percobaan membuat lukisan pada jilbab 
yang dilakukan dengan cukup baik, ke depannya tinggal mereka mengembangkan untuk ukuran yang lebih besar atau dengan menggunakan media yang mereka inginkan dan sesuaikan dengan kebutuhan. Pelaksanaan kegiatan pengabdian masyarakat yang dilaksanakan oleh tim dosen DKV Universitas Indraprasta PGRI pada kesempatan kali ini telah berjalan dengan baik dan kondusif, bahkan ibu-ibu Pkk mendapatkan wawasan baru untuk mengembangkan kreativitas yang inovatif bagi mereka untuk membuat lukis dengan menggunakan cat acrylic dengan media pakaian. Untuk pengabdian masyarakat selanjutnya kami akan mengadakan pelatihan ini ke kelompok ibu-ibu Pkk yang yang lain, agar dengan seni lukis pada jilbab bekas ini dapat menjadi salah satu cara untuk melestarikan seni di Indonesia.

\section{SIMPULAN}

Dalam kegiatan Pengabdian Masyarakat Pelatihan Seni Lukis pada Jilbab dengan menggunakan tisyu motif dan cat acrylic sebagai salah satu cara menggugah kreativitas ibu-ibu Pkk Lestari dan ibu-ibu Pkk Kenanga, memberikan simpulan bahwa kegiatan ini :

1. Jumlah ibu-ibu sebagai peserta yang mengikuti penyuluhan dan pelatihan dalam abdimas ini tidak sesuai dengan jumlah target peserta yang diharapkan, karena banyak ibu-ibu anggota PKK yang mendadak ada urusan keluarga.

2. Peserta tidak memiliki atau menyiapkan perlengkapan alat-alat pembuatan teknik yang kami ingin ajarkan, sehingga karena hanya mengandalkan bahan dan alat dari kami tim Dosen, maka mereka hanya dapat memilih contoh-contoh untuk praktik langsung sesuai dengan yang sudah kami sediakan sehingga mereka tidak dapat bereksperimen bebas sesuai keinginan mereka, dan juga pembuatan seni lukis yang mereka lakukan masih baru sebatas teknik dasar pembuatan yang sederhana saja.

3. Penyuluhan dan pelatihan berjalan dengan baik dan seluruh peserta sangat antusias memperhatikan dan mencoba praktik langsung atas apa yang sudah kami contohkan dalam pelatihan ini.

4. Dalam praktik langsung membuat seni lukis pada jilbab bekas semua sudah berjalan dengan lancar, namun tingkat kesabaran dan ketelitian peserta yang berbeda menjadikan hasil yang mereka dapatkan ada yang bagus ada yang kurang bagus. Hasil praktik langsung peserta dalam membuat lukisan pada kain jilbab kami persilahkan mereka untuk membawanya sebagai kenangan dari kami.

Dalam kegiatan pelatihan seperti ini, sangat baik jika peserta, penyelenggara dan tim dosen bersinergi menyiapkan segala sesuatu lebih baik lagi dan dengan waktu yang lebih panjang, agar tujuan dari kegiatan abdimas ini dapat dilaksanakan secara optimal. Maka saran dari tim Abdimas DKV atas kegiatan ini adalah :

1. Pihak mitra dalam hal ini kelompok ibu-ibu Pkk Lestari dan kelompok ibu-ibu PKK Kenanga mengomunikasikan akan kepastian jumlah peserta, agar tim dapat mempersiapkan perlengkapan sesuai dengan jumlah peserta dikarenakan jarak yang cukup jauh apabila terdapat kekurangan.

2. Untuk kegiatan pengabdian masyarakat ini memang membutuhkan anggaran lebih, dikarenakan peralatan yang digunakan khususnya 
cat acrylic dan tisyu motif harganya sedikit mahal. Maka untuk kegiatan berikutnya sebaiknya para peserta atau mitra turut bersedia menyiapkan bantuan bahan dan alat kelengkapan yang dibutuhkan, maka hasil yang diciptakan akan jauh lebih bagus dan lebih banyak.

3. Hasil dari kegiatan ini berupa keterampilan agar dapat terus di asah, mungkin ibu-ibu bisa mencoba menggunakan media lainnya, seperti pakaian bekas

\section{DAFTAR PUSTAKA}

Djelantik, A.A.M. (1999). Estetika Sebuah Pengantar. Jakarta : masyarakat Seni Pertunjukkan Indonesia (MSPI)
Darmaprawira, S. (2002). Warna Teori dan Kreativitas Penggunaannya Edisi ke-2. Bandung : ITB

Gie, T. L. (1976). Garis Besar Estetik (Filsafat Keindahan) Cetakan ke2. Fakultas. Filsafat Universitas Gajah Mada,

Sujiono, N. (2010). Bermain Kreatif. Jakarta: PT. Indeks.

Rustan, S. (2010). Layout Dasar dan Penerapannya. Jakarta : Gramedia Pustaka Utama.

Internet :

https://www.google.co.id/maps/@ _ 6.5303092,106.8264853,15z 